\title{
Modeling the Organizational Aspects of Learning Objects in Semantic Web Approaches to Information Systems
}

\author{
Miltiadis D. Lytras \\ University of Patras, \\ Patras, Greece
}

\author{
mdl@eltrun.gr
}

\author{
Miguel-Angel Sicilia \\ University of Alcalá, \\ Alcalá, Spain
}

\begin{abstract}
The concept of learning object has become a central notion of the majority of current approaches to e-learning that focus on reusability and automation. Learning object metadata can be considered a driver for mediated resource location, thus fostering the development of digital repositories and intermediaries. Such entities are aimed to collect, store and expose rich learning object descriptions. This has lead to approaches for Semantic Web applications to e-learning that explicitly model learning objects as instances inside formal ontologies, thus representing metadata as logics-based sentences, with such sentences describing digital artifacts in terms of shared conceptualizations of diverse domains. Nonetheless, existing models do not explicitly consider the aspect of "value" inherent to learning processes and artifacts as components inside the context of organizational Information Systems. The Information Systems view regarding learning objects requires a consideration of the learning behavior of the organization as a whole, in which learning objects become critical resources linked to strategic or contingent organizational needs. This paper examines the role of learning objects as elements inside Information Systems, and provides a semantic definition for them that integrate the various aspects of learning processes in the organizational context. In addition, the main elements of a proposed formal ontology of learning objects inside organizational Information Systems are discussed by means of scenarios.
\end{abstract}

Keywords: learning objects, Information Systems, Semantic Web.

\section{Introduction}

The term "information system" (IS) is nowadays a widespread concept, but it is still subject to divergent interpretations. Definitions range from those focused on information technology and computer and network infrastructure to broader ones that include also organizational and social

Material published as part of this journal, either on-line or in print, is copyrighted by the publisher of the Interdisciplinary Journal of Knowledge and Learning Objects. Permission to make digital or paper copy of part or all of these works for personal or classroom use is granted without fee provided that the copies are not made or distributed for profit or commercial advantage AND that copies 1) bear this notice in full and 2) give the full citation on the first page. It is permissible to abstract these works so long as credit is given. To copy in all other cases or to republish or to post on a server or to redistribute to lists requires specific permission and payment of a fee. Contact Publisher@ijklo.org to request redistribution permission. structures. An example of the latter is the one provided by ATIS (http://www.atis.org/) "the entire infrastructure, organization, personnel, and components for the collection, processing, storage, transmission, display, dissemination, and disposition of information". Despite its broadness, this and other definitions still lack an essential element: the explicit reference to the purpose of information systems, i.e. a reference to which 
should constitute the justification and criterion for the analysis and design of IS in organizations. The notion of "value" of IS has been pointed out elsewhere as the mentioned missing teleological aspect, even though the concept is still subject to disparate interpretations (Cronk \& Fitzgerald, 1999). In that direction, the FRISCO project reported by Falkenberg et al. (1998) investigated an interdisciplinary account of the concept as "a system in organizational context, serving to provide value by making information available" (Hesse \& Verrijn-Stuart, 2000). Furthermore, information delivery can be considered as an increment of personal knowledge - and thus of organizational knowledge according to learning organization paradigms (Örtenblad, 2001) - . According to such view, Information Systems are organic part of entities, and the components of IS become elements associated to processes oriented towards some higher-level goals, being these strategic or contingent. This aspect of IS as integral parts of organizations is stressed also in the AIS Model Curriculum IS2002 ("IS2002", 2002), in which it is said that "the effective and efficient use of information and communications technologies is an important element in achieving competitive advantage for business organizations". Here "efficient" and "effective" can be considered as concrete aspects that contribute to the "value" of an IS.

The view on IS described so far is consistent with existing propositions of the concept of learning organizations (Wei-Choo, 2001) and of knowledge management (Lytras, Pouloudi \& Poulymenakou, 2002) that focus on learning processes as essential constituents of organizational activities. Since learning systems can be considered as a specific class of IS, approaches to learning technology and learning design should consider the organizational context, and subsequently, address a value-driven characterization, as stressed by Lytras, Pouloudi and Poulymenakou (2002). Consequently, ontologies associated to e-learning technology or processes should explicitly model one or several notions of value, or at least guarantee that the elements required to assess value as associated to learning are properly represented for subsequent audit and accountability.

In this paper, our main concern is the characterization and assessment of "learning objects" (Polsani, 2003; Wiley, 2001) as pieces used to facilitate organizational learning. The importance of learning objects derives from the fact that reuse is considered as its principal characteristic. For example, Polsani (2003) includes reuse in his definition of learning object as "an independent and self-standing unit of learning content that is predisposed to reuse in multiple instructional contexts", and Wiley (2001) also mentions the term in his learning object definition "any digital resource that can be reused to support learning". This emphasis on reuse has opened expectations for increased automation levels in the selection and composition of Web learning resources that may eventually lead to mass customization (Martinez, 2001). Within the above described view of IS, the role of learning objects acquires a new organizational dimension, linked to processes of information or knowledge assimilation in a broad sense, and driven by organizational behaviour. The planning of learning activities thus becomes a matter of establishing decision frameworks like "knowledge gap analysis" (Sunassee \& Sewry, 2002) associated to competencies, knowledge, abilities or skills (Sicilia, 2005), in which learning objects can be considered as resources (or better, as "assets") available for exploitation.

In consequence, the role of Semantic Web technologies (Berners-Lee, Hendler, \& Lassila, 2001) in learning-oriented views to Information Systems can be considered as that of providing the infrastructure to facilitate the selection, transformation and delivery of information resources inside or outside the organization to fulfil individual needs, that in turn provide a value for the organization as a whole. Such infrastructure requires an ontological model of learning objects that addresses the needs posed by the diverse learning-oriented processes. Existing proposals for such ontological schema (See Lytras, Themistocleous and Tsilira (2003) or Sicilia and García (2005) for recent reviews.) are valuable in translating and refining learning object metadata standards and schemas, but they lack an organizational view. Concretely, the assessment of learning objects with regards to the value provided is not addressed, their integration with Knowledge Manage- 
ment (KM) activities is not explicitly established, and their connection with competency models is not described. Without such elements, ontologies that represent learning objects and related infrastructure lack an explicit integration with the Information System concept, and thus are still not fully prepared for a semantic approach to organizational learning. This paper describes these three aspects and provides a semantic definition for learning objects that properly addresses them. In addition, some of the most important organizational elements surrounding learning objects are also described and contextualized in terms of their role in work scenarios. The result is the sketch of an ontological schema that complements existing ones by providing a strong commitment to the view of a learning organization. The ontological definitions described in the paper are not intended to be definitive or closed-ended. On the contrary, they are posed as tentative definitions to motivate further engineering both in the formal and also in the conceptual aspects of organizational learning. It should be noted also that different theoretical assumptions on learning and cognition may lead to divergent refinements of the core definitions provided here. For example, constructivist or socio-cultural views on learning may emphasize some aspects over others and lead to different schemas, as described by Sicilia and Lytras (2005a). This dimension of ontological commitment is not addressed in detail here, since it pertains to the specifics of designing concrete learning programs or environments, rather than to the global consideration of learning objects as pieces in the strategy and behaviour of change of the organization.

The rest of this paper is structured as follows. The second section describes the overall context of learning objects inside an organizational IS. Then, the connections of the concept of learning object with other ontological definitions are described in the third section. The fourth section addresses the main essential scenarios that should be addressed by Semantic Web technology inside an IS. Finally, conclusions are provided in the fifth section.

\section{Learning Objects in the Organizational Context}

The engineering of an ontology describing the role of learning objects inside IS requires a conceptualization of the whole organizational structure and activities. Figure 1 depicts a simplified view of the main elements that should be taken into account under such view. Processes are depicted as ellipses, and models that require representation are showed as rectangles. The elements in the Figure are a restricted view of the complex structures of an Information System. Thus, we should first clearly state what is an IS for our purposes. If we take the definition of FRISCO "a system in organizational context, serving to provide value by making information available", we should begin by defining the concept of system. According to the International Council on Systems Engineering (2000) a system is "an interacting combination of elements to accomplish a defined objective. These include hardware, software, firmware, people, information, techniques, facilities, services, and other support elements". This definition combined with that of FRISCO leads to a consideration of information systems as a system used by an organization that has the purpose of creating value through the management of information resources. Organizations are yet defined in common knowledge bases like OpenCyc as "group whose group-members are instances of $O C$ IntelligentAgent (terms or relations inside OpenCyc are put in the text in courier font prefixed by "oc", ontology definitions in general are also in courier font, and H\&J definitions are referenced using square brackets for reference). In each instance of oc_Organization, certain relationships and obligations exist between the members of the organization, or between the organization and its members". In consequence, the value-creation objectives of the IS should be aligned to those of the organization in which it is framed, and the

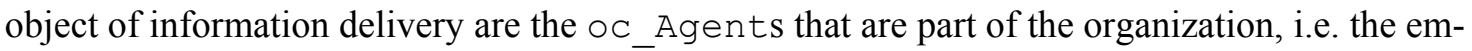
ployees, users or stakeholders.

The realization of the purposeful delivery of information takes the form of concrete activities, i.e. sequences of actions. Some of these actions are realization of processes and procedures, and parts 
of them are specific to the creation of knowledge and abilities applied to work settings, which we will call competencies. Learning activities are thus considered to be the fundamental behaviour of the IS with regards to creating or enhancing value in the form of competencies.

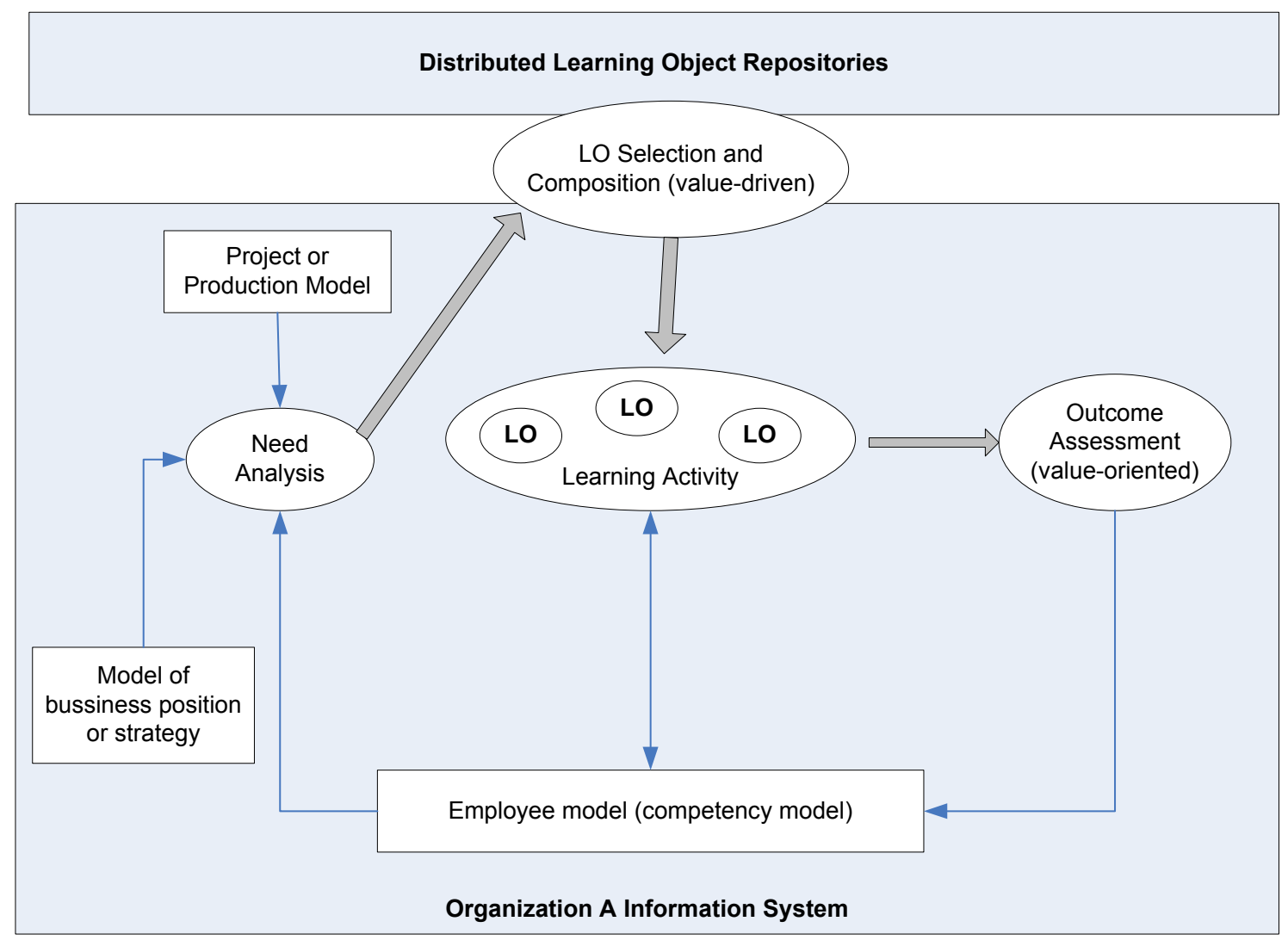

Figure 1. Learning objects in the organizational context of value creation.

In Figure 1, four key generic processes are depicted. "Need analysis" represent the set of processes oriented towards the identification of gaps in organizational capabilities. The origin of needs is diverse, since they may come from contingent or strategic requirements. An example of the former may be that of a concrete skill required for a project that has yet been arranged, or the identification of a concrete knowledge that call-centre operators will require to give support for the new product line of mobile phones. The latter include prospective requirements, e.g. having software architects knowledgeable in the emerging technology of wireless domotic devices, but also more generic statements about desires, e.g. having a more flexible negotiation process in procurement activities. The expression of the sources of needs would require the integration of models of project or production and also of organizational position or strategy. This is due to the fact that learning needs are ultimately justified on requirements to improve workforce capabilities both for immediate tasks inside projects or production chains, and also to anticipate prospective requirements that depend on the positioning and strategy of the organization in its contextual and market circumstances. Such kinds of models are usually available - at least in a non-formal representation - in the definition of business process models inside the organization.

Since needs are of a widely diverse nature, here we will focus on those that are connected with organizational learning processes, using a notion of competency linked to human performance (Rothwell \& Kazanas, 1992) that includes the following aspects:

(a) a "work situation" as the origin of the requirement for action that puts the competency into play 
(b) the individual's required attributes (knowledge, skills, attitudes) in order to be able to act in the work situation

(c) the response which is the action itself,

(d) the consequences or outcomes, which are the results of the action, and which determine if the standard performance has been met.

Learning needs can be expressed in terms of aggregated competency levels which are devices to express the organizational capability to perform with a given standard for a particular work situation, and competency relationships may be taken into account in the assessment of related competencies (Sicilia, García \& Alcalde, 2004). This competency-centric view of learning needs can be considered as reductionistic in the sense that concentrates only on externally visible behaviour but we adhere to it as one of the most common ways of accounting personnel capabilities in organizations.

The competency gap resulting from need analysis then becomes the search criteria for the processes of "Learning Object selection and composition processes" (see Figure 1). This process is value-driven, since learning activities are programmed as a result of a justified organizational requirement that would entail some benefit in terms of results or competitive advantage. Ideally, the system would be able to produce a targeted learning design including the appropriate learning objects and deliver it to the employees that are best suited to acquire the required competencies. In practice, Semantic Web technology (Devedzic, 2004) is able today of helping in the learning design process by retrieving candidate learning objects and suggesting paths to a human designer. After the learning activities take place, the assessment of the outcomes again take into account that the required competencies have actually been acquired, and the organization is in better position to deal with the originating needs.

The ontology of KM elaborated by Holsapple \& Joshi (2004) provides an appropriate conceptual framework to include the notion of learning object as a specialized form of knowledge representations (in the sense of KM management). In what follows, the main elements of the integration of learning objects as part of KM activities are sketched using OpenCyc as a reference framework. A significant amount of reuse in terminological structures and tools can be achieved by building KM systems on top of existing large terminological bases like OpenCyc. OpenCyc is the open source version of the Cyc Knowledge Base (Lenat, 1995). Cyc attempts to provide a comprehensive upper ontology of "commonsense" knowledge. OpenCyc contains many formal definitions that are useful in the development of KM support systems, including basic supporting elements like time and date, descriptions of organizational and customer-related terms, agent-based communication and descriptions of events and activities. What follows is a synthetized version of the model described in (Sicilia, Lytras, Rodríguez, \& García-Barriocanal, in press)

oc_Organization is assimilated to the concept of entity in [DKMC1-5], and represents a group of oc_IntelligentAgents that are Knowledge Processors. Knowledge [DKMC6] in agents can be modelled by oc knows, oc knowsAbout and similar relations, but this is not rich enough to model competency as required by the framework depicted in Figure 1. This can be accomplished by the terms JobSituationDefinition (JSD) and CompetencyDefinition (CD) as the representations of the required performance levels, where requiredIn connects the former with the latter. A CD can be further specified through the concept of CompetencyElement, which subsumes Skill, Knowledge and Ability. The actual competencies, job situations and competency elements are defined by separate classes, thus clearly delineating actual performance from the definitions of stereotyped performance situations that are common in human resource management and project planning. 
Then, the assessment of aggregated competency levels (which in their role of objectives of the organization are defined as a Need) becomes a problem of defining a computation procedure ACL (Employees, CDs, Organization) that yields a value in terms of CD from the aggregation of the competencies of a group of employees. Such level should always be expressed in terms relative to the size and structure of the organization being considered, it may be compensatory or not (Sure, Maedche, \& Staab, 2000), and it could consider the imperfection of competency assessment as a built-in characteristic (Sicilia, García, \& Alcalde, 2004). The definitions for competencies described allow the association of agents inside the organization to competencies through a hascompetency relation, and that competencies are connected to CDs, allowing the actual assessment of gap levels.

H\&J ontology describes KM activity in terms of the manipulation of knowledge representation by processors [DKMC11]. The recognizable kinds of knowledge manipulation are referred to as Knowledge Manipulation Activity (KMA) [DKMC12]. Activities in OpenCyc are represented as oc_Action, which are collections of oc_Event carried out by a "doer". This generic concept of action can be specialized to represent KMA executions by restricting them to be carried out by intelligent agents, e.g. to be oc_PurposefulActions oc_performedBy them. A specific kind of KMA in which we are interested here is that of LearningActivity, which is characterized by having the expectedOutcome of oc Learning, being learning a change in the cognitive state of an agent. Different theories of learning lead to different ontological definitions for the concept of Change, but we will not discuss it here. (See Sicilia \& Lytras, 2005a for details.)

The process of selection and composition of learning objects can be then viewed as KM metaactivities that have the objective of producing LearningDesigns, i.e. the concrete activitybased structure that would be used to facilitate learning. This concept can be easily integrated if we follow the schema provided by the IMS LD specification. IMS Learning Design provides a powerful language for the expression of learning designs targeted at the realization of activities. Here, an activity is considered as a piece of interaction among a number of specified Roles, which produce a tangible Outcome by using a concrete environment. The so-called Environment of a given role is made up of learning objects and Services that are available at runtime. Activities can be further decomposed in sub-activities. They are also aggregated into Methods that specify the conditions for application of the learning design, along with the planned $\mathrm{Ob}-$ jectives that will eventually match the outcomes of the activities. Methods can be structured around concurrent Plays and these in turn in sequential Acts, the latter allowing the specification of execution conditions. The formal LD descriptions provide a standardized and rich way to express learning-oriented KMAs, where objectives and outcomes should be expressed in terms of competency definitions as those described above.

The definitions sketched so far provide the basic elements for the KM-integrated and competency-based view of learning activities. The rest of the paper deals with the definition of learning objects and their value inside the same referential domain.

\section{A Semantic Definition for Learning Objects as Part of IS}

The definition of learning objects as digital artefacts is described by Sicilia, García, SánchezAlonso, \& Rodríguez (2004), in terms of OpenCyc elements, characterizing them as [AKMC2] information bearing things, i.e. each instance of oc_InformationBearingThing (or IBT) is "an item that contains information (for an agent who knows how to interpret it). " This is convenient for the integration of technical descriptions and other metadata elements described in the IEEE LOM standard, which consider learning objects as information resources. The connection 
of learning object with organizational needs is linked by the possibility of expressing outcome and pre-requisite competencies as part of their metadata profile. Concretely, LOM provides a vocabulary element competency in its Classifications category that can be used for that purpose. This definition of Learningobject as a primitive element covers the use of pre-packaged entities with metadata as are retrieved from local or external repositories. In addition, the actual practice of KM activities in many cases results in the use of resources retrieved from the Web or created by the participants. Even though those elements are not formally described by metadata, they are in many cases a source of value. Such elements are integrated in a looser definition of learning objects that subsume the LearningObject concept but allows for accounting other resources that are potential sources of value.

\section{ValueSource $\equiv \forall$ ibtUsed.LearningActivity}

In what follows, we will mention learning objects, but the definitions are also applicable to the subsuming ValueSource concept.

Learning object value is dependant on the value paradigm adopted (Cronk \& Fitzgerald, 1999), and may vary from cost-benefit analysis or return of investment measures to more qualitative and multidimensional frameworks including concepts like utility, alignment with strategy and organizational impact. In any case, those approaches would result in the linking of the effects of using learning objects within the organizational framework. Then, the value of a learning object can be approached from two complementary perspectives:

- The actual value "created" directly or indirectly by its use in learning activities inside the organization.

- The "potential" value of a learning object with regard to a given organizational need.

It should be noted that while the first aspect emphasizes a kind of post-hoc measuring or assessment process, the second one is actually centred on the adequacy of resources for the accomplishment of short or far-reaching organizational goals, so that they lead to different ontological definitions. In what follows, two concrete and simple characterizations of both aspects of value are provided. Even though they are partial in covering the many understandings of IS value, they may serve as a specific point of departure for devising more elaborate ones.

The potential value of a learning object for a given Need is determined by its expected contribution to fulfilling those needs as expressed in their objectives. Then, if we have that a need is expressed as a level in a competency description $\langle\mathrm{C}, \mathrm{L}\rangle$, the learning object contributing value must be connected to $\mathrm{C}$ as one of its objectives to some extent. Nonetheless, since the object $\mathrm{O}$ may contribute to some of the CompetencyElements only, its value may be partial, and learning object composition should take place. There is not a way to represent the extent it contributes to $\mathrm{C}$ if the contributions of each part is not specified in the competency description itself, so that in general we will say that it contributes to $\mathrm{C}$, denoted as $c b(<\mathrm{C}, \mathrm{L}>, \mathrm{O})$. Those contributions lead to value when considering the existing quality criteria $\mathrm{Cr}$ or quality measures $\mathrm{M}$ available, so that the value of the object is finally dependant on the $q t(c b(<\mathrm{C}, \mathrm{L}>, \mathrm{O}), \mathrm{M}, \mathrm{Cr})$. An additional aspect should be considered: given two objects $\mathrm{O} 1$ and $\mathrm{O} 2$, both $\mathrm{cb}(<\mathrm{C}, \mathrm{L}>, \mathrm{Oi})$, it may be possible that one of them provides more value since it fits better the learning style, preferences and/or previous knowledge or abilities of the target employees $\mathrm{E}$ in the organization. Thus, we finally have an expression as value $=\mathrm{v}(q t(c b(<\mathrm{C}, \mathrm{L}>, \mathrm{O}), \mathrm{M}, \mathrm{Cr}), \mathrm{E})$. Such complex setting involves several levels of ontological structures put into play in activities that add constraints to the final assessment. The simple example provided in the following Table aims at illustrating these levels (ontology terms, instances and relations are showed in courier font). 
Table 1: Example descriptions for value-related elements

\begin{tabular}{|c|c|c|}
\hline Ontology elements & Description & Level of description \\
\hline $\begin{array}{l}\text { Organization A requires a } \\
\text { level of about a } 60 \% \text { of its } \\
\text { SalesForce have the compe- } \\
\text { tency of describing potential } \\
\text { customers the comparison be- } \\
\text { tween technologies of mobile } \\
\text { phones (competency definition } \\
\text { TC), aimed at an increase in } \\
\text { product up-selling. }\end{array}$ & $\begin{array}{l}\text { The }<\mathrm{TC}, 60 \%>\text { level is the } \\
\text { requirement. Work context is } \\
\text { that of selling face-to-face or } \\
\text { by phone, basic communica- } \\
\text { tive skills are required, and } \\
\text { the knowledge about the } \\
\text { technical differences is the } \\
\text { main aspect to be mastered. }\end{array}$ & $\begin{array}{l}\text { Requirements in terms of } \\
\text { Needs expressed as Com- } \\
\text { petencyDefinition. }\end{array}$ \\
\hline $\begin{array}{l}\text { As a result of gap analysis, it is } \\
\text { determined that only } 30 \% \text { of } \\
\text { instances of SalesForce are } \\
\text { prepared. A subset of the re- } \\
\text { maining Employees is obtained } \\
\text { as a potential target group for a } \\
\text { LearningActivity. }\end{array}$ & $\begin{array}{l}<\mathrm{TC}, 30 \%>\text { level is the basic } \\
\text { gap, and the target } \mathrm{E} \text { group is } \\
\text { determined. }\end{array}$ & $\begin{array}{l}\text { Competency gap as re- } \\
\text { lated to requirements and } \\
\text { determination of target } \\
\text { group. }\end{array}$ \\
\hline $\begin{array}{l}\text { A search in federated learning } \\
\text { object repositories returns a list } \\
\text { of learning objects, all of them } \\
\text { being relevant to the required } \\
\text { competency. }\end{array}$ & $\begin{array}{l}\text { The set }\{\mathrm{O} i\} \text { of candidate } \\
\text { learning objects is obtained, } \\
\text { all of them being } \mathrm{cb}(<\mathrm{TC} \text {, } \\
30 \%>, \mathrm{O} i) \text {. }\end{array}$ & $\begin{array}{l}\text { Learning object selection } \\
\text { based on needs is carried } \\
\text { out. }\end{array}$ \\
\hline $\begin{array}{l}\text { A sorting of learning objects for } \\
\text { each competency element is } \\
\text { elaborated to help in selection. }\end{array}$ & $\begin{array}{l}\text { The set }\{\mathrm{Oi}\} \text { of candidate } \\
\text { learning objects is divided by } \\
\text { covering each of the compe- } \\
\text { tency elements (in this simple } \\
\text { case, only one), and the qual- } \\
\text { ity is assessed based on a da- } \\
\text { tabase of ratings } \mathrm{R} \text {, resulting } \\
\text { in } q t(c b(<\mathrm{C}, \mathrm{L}>, \mathrm{O}) \text {, } \\
\mathrm{R})\end{array}$ & $\begin{array}{l}\text { A concept of quality of } \\
\text { learning objects, in this } \\
\text { case based on simple rat- } \\
\text { ings, is used for alternative } \\
\text { selection. }\end{array}$ \\
\hline $\begin{array}{l}\text { The value of the objects is as- } \\
\text { sessed taking into account that } \\
\text { the selected employees have } \\
\text { enough time to complete them in } \\
\text { their schedules and that their } \\
\text { difficulty and learning style } \\
\text { match that of the target popula- } \\
\text { tion, which in this case prefers } \\
\text { globally case-based situations. }\end{array}$ & $\begin{array}{l}\text { The final value assessment } \\
\text { takes into account some ele- } \\
\text { ments connected to E. } \\
\mathrm{V}(q t(c b(<\mathrm{C}, \mathrm{L}>, \mathrm{O}) \text {, } \\
\mathrm{R}), \mathrm{E})\end{array}$ & $\begin{array}{l}\text { A concept of value con- } \\
\text { tingent to the concrete } \\
\text { organizational situation } \\
\text { at the present instant of } \\
\text { time is used for the final } \\
\text { decision. }\end{array}$ \\
\hline
\end{tabular}

The schematic example provided represents one of the possible sequences for value-driven selection of learning objects. Many variations and more complex sequences can be devised, but they should ultimately refer to a required value for the organization. The global value produced by the learning activities can then be estimated by aggregation of the contributions of each learning ob- 
ject used, but this approach has the drawback of not considering the activity design or other contextual elements. A component omitted in the example for simplicity was that of the actual design of the learning-object based activity. Such design is also a value driver, since the arrangement of the activities and eventually of the roles played by each participant in them determines to some extent the outcomes of the learning process (Koper, 2004).

Following the definitions in the above example, actual or "created" value can be determined as the difference of the previous and post-activity aggregated competencies that were facilitated by the learning program. The same assessment problems pointed out above still take place in this view, e.g. the assignment of parts of the merit to certain learning objects or to their arrangement in concrete designs, and the determination of metrics of value to distinct competencies or competency-related elements. It should be noted also that potential and actual measures may eventually diverge in a significant amount. This may be considered as an error in pre-assessment, but also as an indicator for some kind of problem in the realization of the activity itself, e.g. due to conflict or contextual work conditions that interfered with the learning process. In the former case, the quality assessment used for the decisions should be traced back in search of possible refinements to the evaluation strategy or measures. In the latter case, some management action could lead to detecting possible areas of improvement in the scheduling, context or conditions of the learning activities, or even to detect problems related to other aspects of organizational activities. It should be noted that the processes of pre and post- assessment thus becomes a systemic adjustment of the organizational behaviour.

The notion of value addressed in the example is related to competency as external, observable behaviour, so that it can be computed by assessing and accounting of competency. This is only a concrete approach, by no means intended to exclude other notions of value. For example, improvement in IS service can be considered also a source of organizational value. If we consider it, the final value measures should be based on some form of indicator of quality of service, e.g. efficiency and precision of responses or even subjective satisfaction measures of the final users.

\section{Main Scenarios for Learning Objects inside Semantic IS}

The use of Semantic Web technology to enhance learning processes inside Information Systems can be materialized in a number of scenarios mediated by semantic tools. In this section we summarize some of the essential ones (see Table 2), sketching an analysis of the ontological structures they should be based on, and some of the determinant of the different levels of "intelligence" that could be associated to them. These different levels of concern have been described by Sicilia \& Lytras (2005b) as "semantic conformance profiles" that entail diverging requirements on the level of description of learning object metadata structures. These levels are intended to reflect the idea that a particular semantic solution to e-learning differs from the others in the richness of aspects considered when taking decisions in the context of the processes sketched in Figure 1. Our intention here is that of providing a roadmap for further research and development activities in the area. 
Table 2: Main learning object-related scenarios inside semantic IS

\begin{tabular}{|c|c|c|}
\hline Scenario & $\begin{array}{l}\text { Ontological structures } \\
\text { involved }\end{array}$ & Levels of "intelligence" \\
\hline $\begin{array}{l}\text { Learning Object Selec- } \\
\text { tion and Composition }\end{array}$ & $\begin{array}{l}\text { Competency definitions, } \\
\text { Needs, Employee Model, } \\
\text { Learning Object Descrip- } \\
\text { tion. }\end{array}$ & $\begin{array}{l}\text { The levels depend on two factors: } \\
\text { - Richness of the aspects considered, e.g. are } \\
\text { learning styles or interaction preferences } \\
\text { taken into account? } \\
\text { - Richness in the level of detail in compe- } \\
\text { tency description, e.g. are basic soft abili- } \\
\text { ties checked for every selection? } \\
\text { - Consideration of employee schedules and } \\
\text { planning of related activities. }\end{array}$ \\
\hline $\begin{array}{l}\text { Integration of Learning } \\
\text { Objects into Learning } \\
\text { Designs }\end{array}$ & $\begin{array}{l}\text { All of the above plus } \\
\text { Learning Activity ontology } \\
\text { and eventually Pedagogy- } \\
\text { specific ontologies. }\end{array}$ & $\begin{array}{l}\text { In addition to the level of description, the con- } \\
\text { sideration of different learning ontologies } \\
\text { (Packer \& Goicoechea, 2000) is here a determi- } \\
\text { nant. }\end{array}$ \\
\hline $\begin{array}{l}\text { Learning object as- } \\
\text { sessment }\end{array}$ & $\begin{array}{l}\text { Learning Object Descrip- } \\
\text { tion plus Quality Criteria. }\end{array}$ & $\begin{array}{l}\text { Depends on the aspect included in the descrip- } \\
\text { tion of quality, including: } \\
\text { - Quality assessments after usage, e.g. rat- } \\
\text { ings or empirical usage data. } \\
\text { - A priori metrics that act as indicators of } \\
\text { quality, e.g. hypermedia structure metrics. }\end{array}$ \\
\hline Need assessment & $\begin{array}{l}\text { Competency Definitions, } \\
\text { Needs }\end{array}$ & $\begin{array}{l}\text { Depends on the level of detail of competency } \\
\text { descriptions, and also in the number and detail } \\
\text { of internal and external, strategic or tactic is- } \\
\text { sues considered as need triggers. }\end{array}$ \\
\hline Gap Analysis & $\begin{array}{l}\text { Competency Definition, } \\
\text { Needs, Employee Model. }\end{array}$ & $\begin{array}{l}\text { Depends on the level of detail of the competen- } \\
\text { cies recorded in the employee model, as long as } \\
\text { in the consideration of related or substitutive } \\
\text { competencies. }\end{array}$ \\
\hline $\begin{array}{l}\text { Learning Activity As- } \\
\text { sessment }\end{array}$ & $\begin{array}{l}\text { Learning Object Descrip- } \\
\text { tion, Quality Criteria, } \\
\text { Learning Activities. }\end{array}$ & $\begin{array}{l}\text { Depends on the level of analysis of empirical } \\
\text { data regarding patterns of learning activity that } \\
\text { lead to better outcomes. }\end{array}$ \\
\hline
\end{tabular}

The main difference between the above scenarios and common learning object location and selection processes is the consideration of both aggregated organizational competency (not as an emergent property but considering the mereology of the system) and also the overall criteria that drive organizational behaviour. This makes learning technology a tool subordinated to concrete, measurable goals, dependant on organizational memory and goals.

Table 2 just sketches some of the dimensions that should be considered for models of learning activities and learning objects that use ontologies as the substrate to provide aid in decision making inside the context of an IS. The tentative definition is provided here as a source for further analysis, extension and critique, with the intention of serving as a point of departure for the engineering of ontologies that put learning objects and activities in the context of value-driven processes. 


\section{Conclusions}

Learning objects in the context of organizational Information Systems can be considered as assets for the accomplishment of higher-level goals connected to organizational behaviour, and more concretely, to learning behaviour. In consequence, the potential value of learning objects within such framework is determined by the needs and activities of the organization (and not only by the quality of their contents), and the actual value created by their usage can be expressed in terms of concrete measures of IS value. This entails that different processes and different quality criteria are required than for the case of general-purpose usage of learning objects, in which an organizational context is not assumed.

Semantic Web technology plays within this organizational framework a role of mediator, providing a degree of automation that facilitates the matching of "valuable" learning objects to contingent or far-reaching needs, and also providing a way to assess the quality of learning objects based on some concrete conception of value creation. For both goals, the ontological representation of value is a requirement, even though a universal definition of value in IS does not exist.

Due to its knowledge-creating nature, the ontology of learning objects inside IS requires the framing of its concepts inside the broader framework of Knowledge Management activities. This has been specified in this paper as a concrete realization of the generic concept of Knowledge Management Activity with a purpose connected to work competencies, thus providing a concrete value-measuring paradigm. In addition, a generic approach to value of learning objects connected to contingent organizational needs has been described, which connect competencies and competency descriptions as the product and requisite of KM learning activities. The framework described here is not intended to be a unique or better solution for the alignment of learning objects inside organizational IS. In contrast, it is only a first attempt to delineate the main elements of such models, which could be used as a point of departure for further research. The method for such further research could proceed by the analysis of available forms of value measuring, and then representing them into frameworks as the one described here. The resulting representations could then be contrasted and refined with regards to their completeness, usefulness and fidelity to the activities and entities being modelled.

\section{References}

Berners-Lee, T., Hendler, J., \& Lassila, O. (2001). The semantic web. Scientific American, 284(5), 34-43.

Cronk, M. C. \& Fitzgerald, E. P. (1999). Understanding "IS business value": Derivation of dimensions. Logistics Information Management, 12(1/2), 40-49.

Devedzic, V. (2004). Education and the semantic web. International Journal of Artificial Intelligence in Education (IJAIED), 14, 39-65.

Falkenberg, E. D., Hesse, W., Lindgreen, P., Nilsson, B. E., Oei, J. L. H., Rolland, C., et al. (1998). FRISCO - A framework of information system concepts - The FRISCO report. IFIP WG 8.1 Task Group FRISCO.

Hesse, W. \& Verrijn-Stuart, A. A. (2000). Towards a theory of information systems: The FRISCO Approach. In Proceedings of the 10th European-Japanese Conference on Information Modeling and Knowledge Bases (EJC 2000), pp. 81-91.

Holsapple, C. W. \& Joshi, K. D. (2004). A formal knowledge management ontology: Conduct, activities, resources, and influences. Journal of the American Society for Information Science and Technology, 55(7), 593-612.

International Council on Systems Engineering. (2000) INCOSE How to: Guide for all engineers, Version 2.

IS 2002: Model Curriculum and Guidelines for Undergraduate Degree Programs in Information Systems. (2002). Available at http://www.aisnet.org/Curriculum/ 
Koper, R. (2004). Use of the semantic web to solve some basic problems in education: Increase flexible, distributed lifelong learning, decrease teacher's workload. Journal of Interactive Media in Education, 6, Special Issue on the Educational Semantic Web. [Available online at http://wwwjime.open.ac.uk/2004/6 ]

Lenat, D. B. (1995) Cyc: A large-scale investment in knowledge infrastructure. Communications of the $A C M, 38(11), 33-38$.

Lytras, M., Pouloudi, A., \& Poulymenakou, A. (2002). Dynamic e-Learning setting through advanced semantics: The value justification of a knowledge management oriented metadata schema. International Journal of e-Learning, 1(4), 49-61.

Lytras, M., Themistocleous, M. \& Tsilira, A. (2003). Towards the semantic e-learning: An ontological oriented discussion of the new research agenda within the e-learning field. In Proceedings of the 9th Americas Conference on Information Systems, (AMCIS 2003), pp. 2985-2997.

Martinez, M. (2001). Mass Customization: Designing for Successful Learning. International Journal of Educational Technology, 2(2). [ Available online at http://www.ao.uiuc.edu/ijet/v2n2/martinez/index.html]

Örtenblad, A. (2001). On differences between organizational learning and learning organization. The Learning Organization, 8(3), 125-133.

Packer, M. \& Goicoechea, J. (2000). Sociocultural and constructivist theories of learning: Ontology, not just epistemology. Educational Psychologist, 35(4), 227-241.

Polsani, P. R. (2003). Use and abuse of reusable learning objects. Journal of Digital information, 3(4), Article No. 164, 2003-02-19. [Available online at http://jodi.ecs.soton.ac.uk/Articles/v03/i04/Polsani/]

Rothwell, W. \& Kazanas, H. (1992). Mastering the instructional design process. Jossey-Bass, San Francisco, CA.

Sicilia, M. A. (2005). Ontology-based competency management: Infrastructures for the knowledgeintensive learning organization. In M. D. Lytras and A. Naeve (Eds.), Intelligent learning infrastructures in knowledge intensive organizations: A semantic web perspective (pp. 302-324). Hershey, PA: Idea Group.

Sicilia, M. A. \& García, E. (2005). On the convergence of formal ontologies and standardized e-learning. Journal of Distance Education Technologies, 3(2), 12-28.

Sicilia, M. A., García, E. \& Alcalde, R. (2004). Fuzzy specializations and aggregation operator design in competence-based human resource selection. In Proceedings of the 8th World Federation on Soft Computing Conference, Springer, NY.

Sicilia, M. A., García, E., Pagés, C., \& Martínez-Herráiz, J. J. (2005). Complete metadata records in learning object repositories: Some evidence and requirements. International Journal on Learning Technology, 1(4), 411-424.

Sicilia, M. A., García, E., Sánchez-Alonso, S. \& Rodríguez, E. (2004). Describing learning object types in ontological structures: towards specialized pedagogical selection. In Proceedings of ED-MEDIA 2004 World conference on educational multimedia, hypermedia and telecommunications, Lugano, Switzerland, pp. 2093-2097.

Sicilia, M. A. \& Lytras, M. (2005a). On the representation of change according to different ontologies of learning. International Journal of Learning and Change, 1(1), 66-79.

Sicilia, M. A. \& Lytras, M. (2005b). Scenario-oriented reusable learning object characterizations. International Journal of Knowledge and Learning, 1(4), pp. 332-341.

Sicilia, M. A., Lytras. M., Rodríguez, E. \& García-Barriocanal, E. (in press) Integrating descriptions of knowledge management learning activities into large ontological structures: A case study. Data and Knowledge Engineering. [Available online at: http://www.sciencedirect.com/science?_ob=GatewayURL\&_method=citationSearch\&_urlVersion=4\& 
_origin=SDTOPTWOFIVE\&_version=1\&_piikey $=\mathrm{S} 0169023 \mathrm{X} 0500042 \mathrm{X} \& \mathrm{md} 5=77 \mathrm{cc} 9608 \mathrm{e} 05067534$ 364ae153ddc94ac ]

Sunassee, N. \& Sewry, D. (2002). A theoretical framework for knowledge management implementation. In Proceedings of the 2002 annual research conference of the South African institute of Enablement through technology, pp. 235 - 245.

Sure, Y., Maedche, A. \& Staab, S. (2000). Leveraging corporate skill knowledge - From ProPer to OntoProPer. In D. Mahling \& U. Reimer (Eds.), Proceedings of the Third International Conference on Practical Aspects of Knowledge Management (PAKM 2000), pp. 30 - 31.

Wei-Choo, C. (2001). The knowing organization as learning organization. Education+Training, 43(4/5), 197-205.

Wiley, D. A. (2001). The instructional use of learning objects. Bloomington, IN: Association for Educational Communications and Technology.

\section{Biographies}

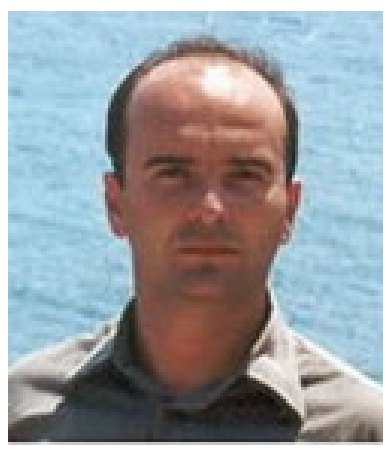

Dr Miltiadis D. Lytras is a faculty member in both the Computers Engineering and Informatics Department (CEID) and the Department of Business Administration at the University of Patras. His research focuses on Semantic Web, knowledge management and e-learning, with more than 70 publications in these areas. He has co-edited thirteen special issues in international journals and authored/edited six books. $\mathrm{He}$ is the founder of the Semantic Web and IS SIG in the Association for Information Systems (http://www.sigsemis.org). He serves as the Editor-in-Chief for three international journals, and as editor or EB member in seven other journals.

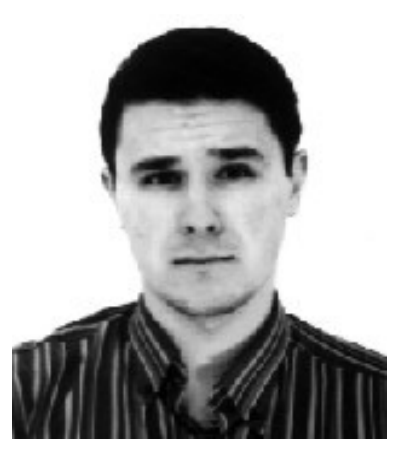

Dr Miguel A. Sicilia leads the Information Engineering Unit at the Computer Science Department, University of Alcalá. His research interests are primarily in the areas of adaptive hypermedia, learning technology and human-computer interaction. He is co-author of more than twenty refereed publications in these areas, and he also leads the SIG on reusable learning objects (http://www.sigrlo.org). 